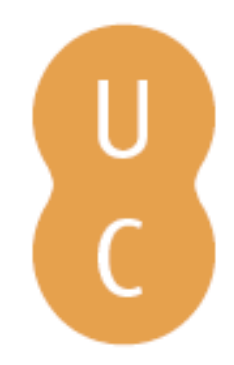

\title{
Rompalina
}

\section{Ezio de NiccoloJommelli para Lisboa: mediação entre a tradição e a inovação}

\author{
Autor(es): $\quad$ Páscoa, Márcio
}

Publicado por: Imprensa da Universidade de Coimbra

URL

persistente: URI:http://hdl.handle.net/10316.2/30042

DOI: $\quad$ DOI:http://dx.doi.org/10.14195/978-989-26-0567-8_12

Accessed : $\quad$ 26-Apr-2023 16:36:31

A navegação consulta e descarregamento dos títulos inseridos nas Bibliotecas Digitais UC Digitalis, UC Pombalina e UC Impactum, pressupõem a aceitação plena e sem reservas dos Termos e Condições de Uso destas Bibliotecas Digitais, disponíveis em https://digitalis.uc.pt/pt-pt/termos.

Conforme exposto nos referidos Termos e Condições de Uso, o descarregamento de títulos de acesso restrito requer uma licença válida de autorização devendo o utilizador aceder ao(s) documento(s) a partir de um endereço de IP da instituição detentora da supramencionada licença.

Ao utilizador é apenas permitido o descarregamento para uso pessoal, pelo que o emprego do(s) título(s) descarregado(s) para outro fim, designadamente comercial, carece de autorização do respetivo autor ou editor da obra.

Na medida em que todas as obras da UC Digitalis se encontram protegidas pelo Código do Direito de Autor e Direitos Conexos e demais legislação aplicável, toda a cópia, parcial ou total, deste documento, nos casos em que é legalmente admitida, deverá conter ou fazer-se acompanhar por este aviso.

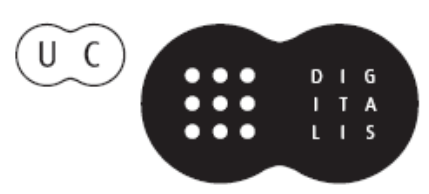




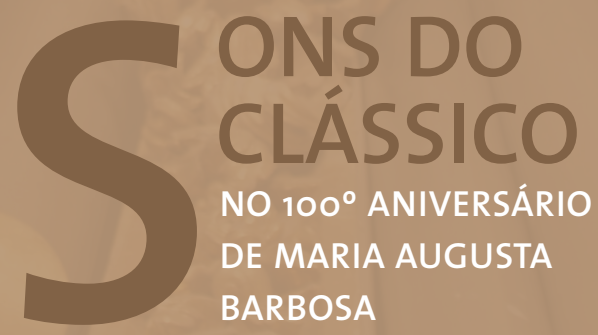

J. M. Pedrosa Cardoso

Margarida Lopes de Miranda COORDENAÇÃO 


\section{Márcio Páscoa}

Universidade do Estado do Amazonas

\section{EZIO DE NICCOLO JOMMELLI PARA LISBOA: MEDIAÇÃo ENTRE A TRADIÇÃO E A INOVAÇÃo}

Em 1753, gozando do auge da fama, Niccolo Jommelli (1714-1774) já havia produzido quase quatro dezenas de óperas, algumas em segunda versão, dentre o gênero sério e cômico, para diversos palcos italianos, os mais prestigiosos. A repercussão de sua obra trouxe-lhe convites de Mannheim e Lisboa, declinados em favor de Stuttgart. O que parece ter-lhe atraído nesta proposta foi a possibilidade de trabalhar coros, balés e conjuntos concertantes, uma vez que o gosto francês nos nobres mandatários desta cidade já estava sendo cultivado a certo tempo. Isto não impediu o autor italiano de desenvolver parceria com Lisboa, já iniciada no ano de 1751 (McClymonds, 1980: p. 20), pelo que consta da existência de libreto desse ano para um componimento drammatico com música de sua autoria.

Embora não tenha se favorecido de tantas obras líricas em estréia como a corte germânica, Lisboa assistiu à montagem de 25 trabalhos de Jommelli, excetuando-se composições de menor dimensão, volume provocado pelos altos encômios, sobretudo na fase em que a relação do autor italiano com Stuttgart se desgastou e ele teve de retornar a Nápoles.

Dentre as óperas criadas especialmente para Lisboa, contam-se, dois trabalhos maduros, a festa teatral L'avventure di Cleomede, de grande dimensão e liberdade formal, e Il trionfo di Clelia, cuja repercussão chegaria ao autor apenas um mês antes de sua morte. Além disso, houve uma encomenda especial, para que o compositor fizesse uma nova versão de Ezio, de Metastasio.

Ezio foi uma escolha pessoal de Dom José e envolvia grandes dificuldades. Em correspondência a Gaetano Martinelli, libretista de sua confiança que 
ele fizera empregar em Lisboa para cuidar dos aspectos de montagem de sua obra, Jommelli confidenciaria:

Ó Deus, quando eu penso que eu tenho de escrever de novo esta ópera, e que eu tenho ainda mais de a escrever para um Soberano ilustrado, Conhecedor, que tem toda a outra Música minha, feita para as mesmas palavras, isto me dá febre. Eu amo, venero e me ajoelho diante do adorado Metastasio e toda a sua obra, mas gostaria que também ele, adaptando-se à moda, fizesse algo novo, assim como é o desejo de todo o mundo querer o mesmo. Assim, posto que eu tenha de extrair tantas diferentes idéias, não somente diferentes das já feitas nas mais vezes, mas também daquelas de outros tantos Compositores, sempre e sempre sobre as mesmas palavras; é coisa para fazer a cabeça rodar, ainda que a tivesse de bronze. Basta. Eu me recomendarei a Apolo e à minha amada Euterpe. (Idem, pp. 487-488)

Com uma enormidade de títulos apresentados ou adquiridos para os próprios arquivos, a ópera de corte no reinado de Dom José fora feita por interveniência direta do soberano nas escolhas mais diversas, de recursos humanos e materiais, de temas e gostos ali praticados. Mesmo que não fosse ele uma figura de elogiável atributo físico, o carisma que concentrava todas as atenções, era considerado conversador erudito ainda que modesto (Monteiro, 2006: p. 65).

Compreendidas as colocações de Jommelli na carta a Martinelli, a respeito do rei português, cabe ainda refletir pelo segundo aspecto do temor do músico. O libreto de Ezio já havia sido trabalhado por ao menos outros 32 compositores além de Jommelli, e a bem da verdade outros 11 ainda o fariam até a derradeira criação de Mercadante em 1827.

Mas com exceção deste último e de Anfossi, nenhum outro autor posterior a Jommelli foi alguém da mesma nomeada. O que preocupava Jommelli seguramente eram as significativas marcas precedentes que obraram sobre o tema. Quando ele fez a sua primeira versão de Ezio, o primeiro grande trabalho de Metastasio que ele abordaria, outros oito autores já se haviam arriscado no tema, dentre os quais Porpora, Hasse e Handel. E até a data em que recebeu a comissão para Lisboa, nomes da envergadura de Sarri, Traetta, 
Graun, Galuppi, Bertoni, De Majo e até Perez, haviam estreado sua versão de Ezio, e Sacchini, Gazzaniga e Guglielmi estavam a preparar a sua.

Havia ainda exigências adicionais de Dom José, que logo de início encarregara Martinelli em escrever uma opera seria "de acordo com o gosto moderno, mas sem representação de bailados» (McClymonds: p. 601) e que o argumento viesse de "qualquer Fábula, ou História, na qual possam entrar tercetos, quartetos, quintetos» (Idem).

O próprio rei dias mais tarde escolheria Ezio como sendo o libreto em questão e a data de 6 de junho de 1771, seu aniversário, foi estabelecida como a estreia desta nova versão, cabendo prioridade em sua composição perante a da ópera de argumento totalmente novo, que viria a ser L'avventura di Cleomede.

Botelho, diretor dos teatros reais, informou que o libreto de Ezio havia sido encurtado pela mão do próprio Metastasio (Idem).

Mas quando Jommelli recebeu o libreto de Ezio, já modificado por Martinelli, é difícil crer que Metastasio concordasse com o que ali estava. O célebre poeta discordaria de outra adaptação, feita por Saverio Mattei, em Ezio naquele mesmo ano, para música de Sacchini. Metastasio refere-se a um quarteto inserido no segundo ato como sendo decente e bem feito, e que dependendo dos cantores podia ser bastante eficaz para os efeitos dramáticos, mas que isso encurtaria o ato, deixando aos dois personagens principais apenas uma ária cada. (Carta de Metastasio a Mattei in McClymonds.)

Isto teria sido um sacrilégio, quando eu o escrevi, mas nos presentes dias, quando nossos cantores heróicos, têm cedido a responsabilidade de uma bem sucedida representação a bailarinos, e quando por virtude desta cessão, a ópera tem se tornado intermezzi para as danças, quanto mais se corta um drama, menos matéria permanece para exercitar a paciência dos espectadores. Por outro lado é falso supor que eu já tenha feito um quarteto para o Ezio e mesmo que eu já tenha sido pedido a fazê-lo.

Parece assim claro que Metastasio não aprovaria também a versão de Martinelli, que também inseriu um quarteto no fim do segundo ato, eliminando árias de vários personagens, como fizera Mattei. A confusão, entretanto, pode ter vindo do próprio Mattei, que afirmou posteriormente ter Metastasio escrito 
uma nova ária para Fulvia, a pedido de Jommelli, para aquela produção de Lisboa. (Idem, p. 198) Trata-se certamente da ária Tenneró per l'idol mio, inserida na cena sétima do segundo ato em lugar de Quel fingere affetto. Jommelli confirmaria em carta a Martinelli que recebera o libreto do amigo ainda em novembro de 1769 , e que, embora sem ter se detido nele, havia considerado que estava muito bom, dando a entender que não havia ninguém entre eles na feitura do Ezio de Lisboa.

A versão de Martinelli para Jommelli tem vários cortes com o fito de promover o citado quarteto no final do segundo ato e ainda um dueto no final do primeiro ato.

Quadro 1 - Comparativo de cenas e árias entre o libreto de Metastasio, 1728 e o de Martinelli, 1772.

\begin{tabular}{lccccc} 
& \multicolumn{2}{c}{ Ezio: Metastasio, 1728 } & \multicolumn{2}{c}{ Ezio: Martinelli, 1772 } \\
\cline { 2 - 5 } & Cenas & Árias & Cenas & Árias/ensembles \\
\hline Ato 1: & 13 & 10 & 10 & 6 \\
\hline Ato 2: & 16 & 10 & 10 & 8 \\
\hline Ato 3: & 15 & 8 & 10 & 4 \\
\hline
\end{tabular}

Quando recebeu o libreto de Ezio em novembro de 1769, Jommelli estava ocupado escrevendo árias para La schiava liberata e ainda por boa parte do primeiro semestre de 1770 , para La Nitteti, ambas destinadas à Lisboa, com adaptações específicas para os cantores e a orquestra da corte portuguesa.

Ezio deveria ter sido acabada em novembro de 1770, de modo a que pudesse estar nas mãos de Dom José em dezembro daquele ano. Mas houve vários motivos de atraso. O primeiro deveu-se seguramente à doença do compositor, que o impossibilitava periodicamente de trabalhar, agravada por sangrias receitadas pelo médico. As pendências financeiras de Stuttgart, ou seja, a recusa de Carl Eugen de Wurtenberg em pagar o acordado com o compositor, deve ter sido o principal motivo para Jommelli passar a escrever óperas para o Teatro San Carlo de Nápoles também naquele ano, o que trouxe preocupação a Botelho.

É verdade que em outubro já estavam prontos todos os recitativos, simples e acompanhados, da ópera, assim como a sinfonia, a marcha e o coro. 
Entretanto, esta que seria a primeira remessa, estava com seu envio atrasado porque Jommelli esperava concluir o primeiro ato para que o rei português não visse a ópera em pedaços. (Idem)

Obviamente, a pressão de Nápoles para que Jommelli escrevesse Demofoonte roubava tempo precioso para cumprir o contrato com Lisboa. Ainda assim, ele conseguiu despachar para Portugal, através de Gênova, a partitura completa e autógrafa de Armida abbandonata, um grande sucesso daquele mesmo ano.

O primeiro ato de Ezio seguiu somente em 20 de novembro daquele ano de 1770 (McClymonds: p. 527). Mas em fins de janeiro de 1771, diante da surpreendente notícia de que o compositor estava engajado também numa ópera para Roma, as cobranças de Lisboa aumentaram (Idem: p. 630) A chegada de uma correspondência em 22 de fevereiro, contendo apenas os recitativos do segundo e do terceiro atos, levou Botelho à indignação:

Quem diria senhor Jommelli que ao invés de receber o resto de toda a ópera Ezio eu iria encontrar apenas os recitativos do ato $2^{\circ}$ e $3^{\circ}$ que o senhor agora me manda, sem nenhuma das árias respectivas? Quem não esperaria uma simples falta, por causa das suas deploráveis doenças acenadas do senhor, mas se se vêem três óperas feitas em Itália, por outros teatros? Quem podia imaginar, que o senhor Jommelli preferiria o venal teatro de Roma ao Real Teatro de S.M.F. [Sua Magestade Fidelíssima] que lhe providenciou uma pensão de 400 zecchini, que lhe foram acrescidos depois de se contentar com 300? (Idem, p. 632)

Como o aniversário da rainha era em 31 de março e por causa do cancelamento da restante temporada do carnaval pelo falecimento da princesa Maria Francisca Doroteia, Botelho decidiu que o aniversário real assistiria a Semiramide riconosciuta e a data de Ezio seria o natalício de Dom José, a 6 de junho.

Botelho esperou até o último momento a chegada das restantes árias de Ezio, talvez postadas em correspondência perdida que Jommelli reclamou ter enviado pelo correio espanhol em dezembro de 1770, janeiro e fevereiro de 1771 (McClymonds: p. 106). 
O aniversário do rei foi preenchido com La clemenza di Tito e, para sorte de Jommelli, o agrado real foi tanto que Dom José deixou que a falta de Ezio apenas se resumisse numa reprimenda ao compositor e não na quebra de contrato como Botelho avisara (Idem).

Após vários revezes, a composição de Ezio seria concluída em 1771 e entrou enfim em ensaios no ano seguinte, indo à cena em 20 de abril de 1772, a comemorar o aniversário da rainha; Botelho comentou em carta a Jommelli que «os músicos acharam-na [a ópera] muito bonita e pelo que espero que Suas Magestades tenham motivo de admirar sempre mais o seu particular talento." (McClymonds 1980: p. 658).

Curiosamente, nem toda a música desta versão de Ezio é nova. Os motivos para isso podem ter sido os contratempos relatados nas cartas entre Botelho, Martinelli e Jommelli, levando-se em conta a pressão por compor algo mais para libreto tão demandado. Entretanto, após tantas faltas, mesmo que abonadas por sucessos levados à cena, pareceria imprudente da parte do italiano que apresentasse um conjunto em que figurassem árias já conhecidas, causando certo descrédito das suas faculdades criativas, conforme comprovadamente ele temia. Mas houve material que foi simplesmente reaproveitado e permanece incerto qual o contexto em que isto se inseria agora em 1772, se no de um procedimento de pasticcio de si mesmo praticado por Jommelli, ou se revisitando aspectos estilísticos mais antigos com intenções estéticas de obter contraste ou reforço retórico sobre algum personagem.

Por exemplo, a ária de Fulvia, Non son io che parlo, no final do Ato III, é quase igual desde a versão de Nápoles (1748), tendo passado por Stuttgart (1758) e chegado à versão de Lisboa (1772), com acréscimo de trompas e oboés, uma parte mais independente de viola, sendo que houve também uma troca de da capo para dal segno. Entretanto, o recitativo que lhe antecede na composição da cena, Misera dove son, foi inteiramente refeito desde a versão napolitana, ainda que tenha permanecido a ideia de ser um obligatto. Jommelli quis manter no plano de cena a ideia original, para enriquecê-la, atualizá-la esteticamente, mas na verdade a escrita homorrítmica muito em voga três décadas antes, já podia ser considerada algo datada. A menos que significasse manutenção de valores que se associava à personagem de grande retidão moral que é Fulvia. 
Como apenas esta cena e mais três árias e um dueto sobrevivem da versão de Stuttgart, pouco se pode saber sobre o material imediatamente prévio que Jommelli realmente aproveitou para a versão de Lisboa. A distância entre a estreia de Lisboa e a de Nápoles, de 24 anos, não deve ter favorecido aproveitar muito mais que as árias do terceiro ato, todas com características de obras mais antigas.

Ainda assim, a preocupação primeira de Jommelli foi com os recitativos. Deviam carregar o drama e a sua feitura correta muito ajudaria no sucesso da obra, no aspecto dinâmico, teatral dela. O compositor decidiu-se certamente onde eles ganhariam estrutura seca, apenas suportada pelo baixo contínuo, ou acompanhada pela orquestra, à vista de terem sido substancialmente modificados pela adaptação de Martinelli. Esse parece ter sido um ponto de preocupação de Jommelli em anos precedentes também, quando fazia em média quatro obbligatti a cada ópera e chegou a dobrar esta conta em produções anteriores.

Jommelli escreveu seis obbligatti em Ezio. Tais recitativos visam dar maior poder dramático à cena e, portanto, localizam-se todos em situações de grande tensão. O primeiro está no encontro de Ezio e Valentiniano logo no primeiro ato e antecede a primeira ária deste último. Ainda neste ato, na primeira cena de Massimo há outro obbligatto, assim como na cena do dueto, em que o par central está sob grande pressão. Da mesma forma, ocorre no quarteto final, onde Valentiniano chama Ezio à sua presença para atribuir-lhe a punição. O imperador quer que Ezio veja Fulvia a seu lado. Mas esta, não podendo mais suportar a simulação revela a todos que ama Ezio. Neste momento o recitativo seco converteu-se em obbligatto, acompanhando a subida de tensão no conflito vivido pelos personagens.

Fulvia ainda está envolvida em mais um obbligatto na sua cena solo do terceiro ato. Costumeiramente apenas os papéis principais têm recitativos deste tipo que lhes são atribuídos, mas Jommelli escreveu um para a cena solista de Varo, onde se encontra a única ária a que ficou reduzido este personagem nesta versão de Lisboa.

As árias, ainda que se possa flagrar material pré-existente, de um modo geral tiveram um tratamento diferente do que à época da versão napolitana. Em alguns casos elas são diametralmente diferentes. A primeira ária do personagem 
titular, Pensa a serbarmi, o cara foi modificada completamente desde a última versão disponível e mesmo o caráter mais juvenil desta música mudou para algo mais maduro e reflexivo na versão de Lisboa.

Há outros aspectos inovadores nesta versão de Ezio para Lisboa. A textura orquestral tende a exceder a divisão em três partes, que era comum neste repertório, especialmente até meados do século. Tais opções comumente incluíam: colla parte de violinos e linha vocal, com viola e baixo contínuo desempenhando partes independentes; e colla parte de violino 1 ou 2 com o solista de canto, enquanto viola e baixo contínuo desempenham a mesma linha.

Jommelli escreveu passagens em textura a 4 vozes, tornando o violino 2 independente e atribuindo uma parte de viola diferente do baixo contínuo. Neste caso a linha vocal dobra a melodia do primeiro violino. O exemplo abaixo vem da ária Nocchier che si figura (Ato I), de Massimo, onde se pode ver o fim de uma seção, marcada pela fermata e o início de um verso que sugere uma escrita psicologicamente mais densa.

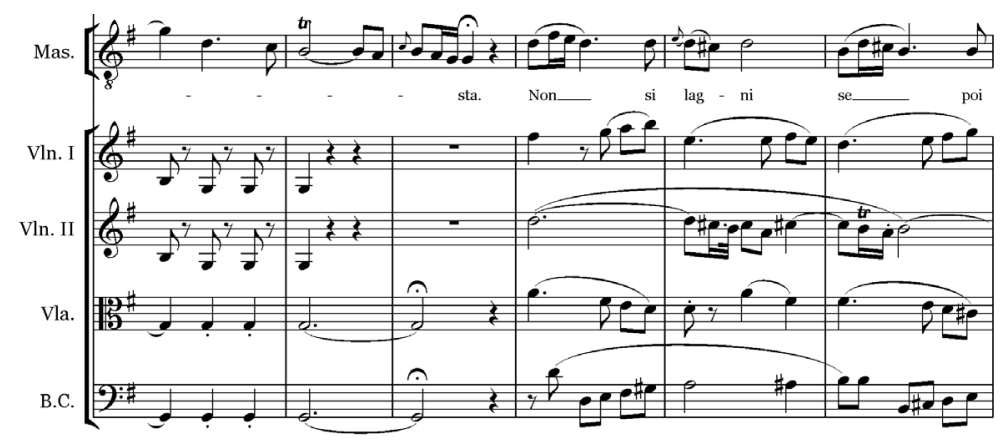

Neste caso, não só as vozes têm independência de notas como tendem a um contraponto bem mais rico do que experimentavam muitos outros autores.

Outra possibilidade de obter uma textura mais rica era pela inclusão eventual de um instrumento solista. O violoncelo é uma escolha natural em diversos autores por ser um elemento destacável do baixo contínuo sem que ocorra prejuízo de orquestração como a princípio se poderia pensar da escolha das demais partes. Assim, o autor chega a obter uma textura a 4 partes, como acontece na ária de Onoria, Quanto mai fellice siete (Ato I) 


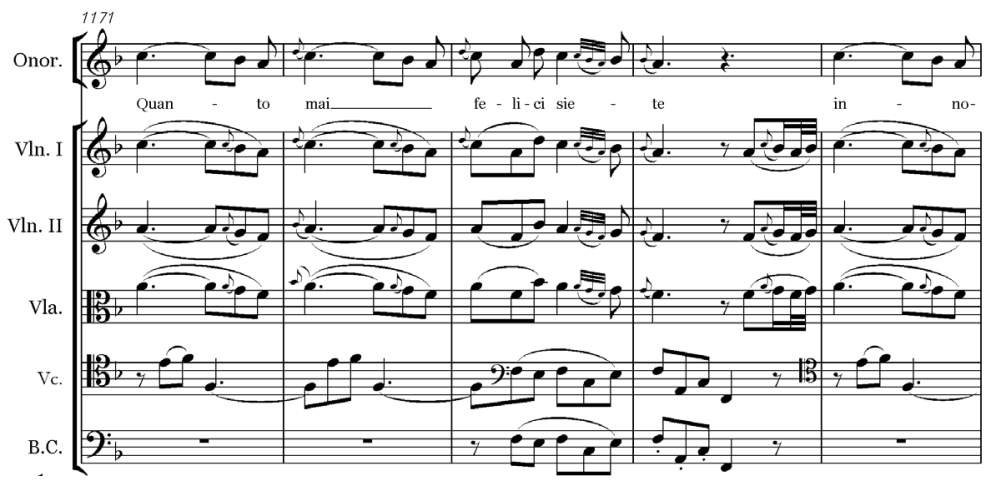

A ária de Onoria simula ainda a idéia de textura a 5 partes por alternar a presença do baixo contínuo com o violoncelo solo. Neste caso a linha vocal continua em colla parte com o primeiro violino.

Entretanto, uma escolha mais ousada vem da mesma ária de Massimo citada acima, em que a textura a 5 partes existe realmente, pois a parte das cordas foi escrita com independência entre si e da linha de canto. O apoio do cantor neste caso está na escrita rítmica coincidente com parte de violino 1 e 2 que pode se alternar como referência ou se manter por mais tempo tendo um naipe como escolha. Viola e baixo contínuo permanecem com escrita independente todo o tempo.

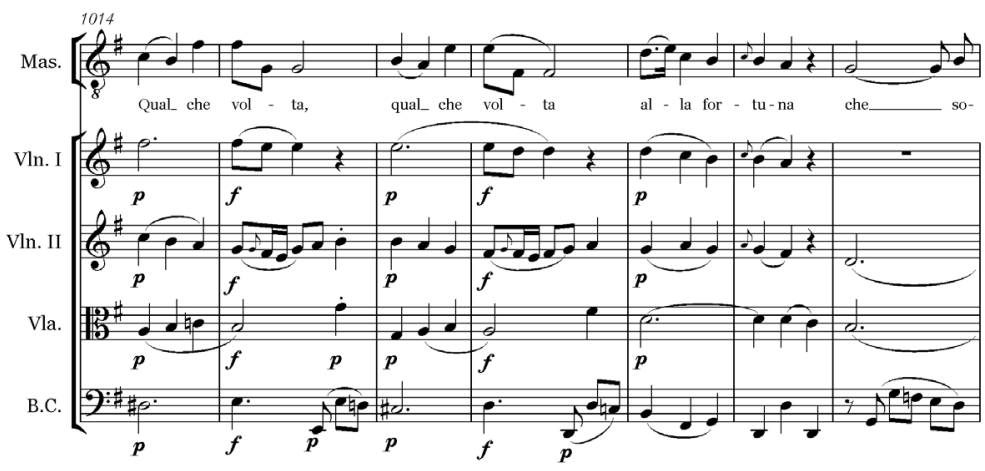

A orquestração de um modo geral é mais rica nas óperas que Jommelli fez para Lisboa, em parte porque ele já possuía uma orquestra bastante seleta em 
Stuttgart, para quem escreveu muitos anos, mas também porque a orquestra de Dom José era ainda maior e mais variada que a do Duque Carl Eugen.

Sob a ótica de vários observadores, a Orquestra da Real Câmara de Lisboa estava entre as melhores se não era a melhor de seu tempo, casos dos testemunhos de Richard Twiss, William Beckford, duque de Chatelet, James Murphy e Adrien Balbi, todos em função diplomática ou militar oficial na capital portuguesa, a escrever memórias posteriores de suas viagens.

Richard Twiss, em particular, escreveu sobre uma performance de Ezio que assistiu em 1772: Eu estive em 17 de novembro no Palácio do Rei em Belém, cerca de cinco milhas de Lisboa, e ouvi a ópera italiana Ezio executada lá. A orquestra consistia de instrumentistas muito habilidosos (Twiss 1775: p. 10).

Jommelli escreveu 9 das 16 árias de Ezio usando oboés e trompas na orquestração, assim como no coro final, na sinfonia de abertura e na marcha, onde além destes incluiu partes independentes para duas flautas. Muitas passagens ao longo da ópera mostram também que o baixo contínuo previa fagotes. Entretanto não há menção alguma a clarinetes, o que completaria o naipe das madeiras, talvez porque Jommelli não os possuísse em Stuttgart e não tivesse o hábito de escrever para tais instrumentos. Ainda assim eles estavam disponíveis na orquestra de Dom José.

O aspecto morfológico das árias escritas por Jommelli em Ezio também reforça a ideia de que se trata de trabalho daqueles últimos anos, em que ele varia consideravelmente de opções e tende a constituir conjuntos mais escorreitos e sem interrupções para mudança de andamento ou caráter.

Não há mais nenhuma ária com a indicação da capo e apenas a citada ária de Fulvia tem a observação dal segno. Quase todas ainda remetem ao padrão $a b a$, ternário composto, com uma seção $a$ dividida em dois $\left(a, a^{\prime}\right)$ por causa da repetição da primeira quadra da ária transitando de tônica para dominante. Algumas vezes o retorno após a seção $b$ traz mais variantes de $a$, podendo haver $a$ " e $a$ "'. Oito árias ainda têm uma seção $b$ definida, com mudança de andamento e formulação de compasso, sendo algumas dentro de ambiente tonal estável. Entretanto outra parte considerável possui elisão entre as seções de modo a não fazer parar o percurso da música. Este procedimento também facilitou a flutuação tonal na escrita de algumas delas, que 
gozam de maior sinuosidade melódica e mais expressividade na disposição do texto sobre a música.

Mas em alguns destes casos, Jommelli também variou o andamento com a inserção de fermatas ou indicações eventuais neste sentido, alterando também os aspectos rítmicos da escrita. Isso pode ter relação com a escolha dos andamentos. Ao menos 6 árias têm a indicação de Andante e Andantino Affetuoso. Embora o Allegro apareça como a escolha comum às demais árias, ao menos 3 delas têm a ressalva complementar de Moderato e algumas ainda têm a indicação de non Presto. Em quase todos os casos as seções internas das árias caem para andamentos mais lentos, como o Andantino.

As indicações de forte e piano, a Jommelli atribuídas como sendo um precursor de seu uso, parecem estar mais relacionadas aqui aos acentos musicais de determinadas passagens, para criar um sotaque correto do discurso musical pretendido. Assim os acentos auxiliam o entendimento do discurso musical e são coerentes com o discurso verbal desenvolvido pelo cantor.

Entretanto, como a versão de Lisboa é uma cópia da mão de João Cordeiro da Silva, o diretor da Orquestra da Real Câmara, é especulável que tais sinais podem variar pela aplicação da idéia de similaridade entre trechos que o autor escreveu e onde podem ser aplicados. No mesmo sentido, há um grande número de ligaduras, sendo boa parte delas para agrupar mais que as notas, abrangendo as ideias musicais de uma passagem ou seção, antecipando tendências românticas.

Jommelli tem nisto e noutros elementos já citados uma proximidade com a escrita musical centro-europeia do tempo, especialmente na preferência por desenvolvimento harmônico sofisticado e até mesmo alguma flutuação cromática. Algumas árias inclusive começam na dominante para se acomodar na tônica e não são raras as passagens em que se encontram as mudanças cromáticas «bruscas», o que se pode verificar nas duas primeiras árias de Fulvia.

A escolha do formato de árias compostas (ternária ou binária) favorece tais ideias, em que uma seção elide na outra, ou mesmo quando ele recorre à alteração da ordem das palavras nos versos, causando efeitos de tensão, ou prolongamento das ideias musicais (Por ex: ária de Fulvia, Tenneró dell'idol mio, Ato II). 
Há uma atribuição parcimoniosa das árias de bravura. Das árias de Valentiniano, seguramente a primeira Se tu la reggi al volo, é a que requer maior demanda de agilidade, não obstante a cadência da ária So chi t'accese precisar de especial cuidado. As duas árias entretanto têm aspecto bastante diferente. Ambas no primeiro ato servem a momentos e características distintos da composição dramática. A primeira explora o caráter impulsivo do imperador, com sua seção central bastante contrastante, representando a sua vacilante e temerosa personalidade. A segunda ária já é marcada por uma escrita pontuada e um andamento bem menos rápido, dando um ar de ária parlante que Jommelli explorou de diversas maneiras em sua obra.

Ezio também possui coloraturas, especialmente nas árias do segundo e terceiro ato. Nesta última em especial, embora uma ária curta para os padrões, os trechos exigem uma voz leve, ainda que no todo, o personagem esteja num registro mais baixo que Valentiniano e Fulvia. Mas Ezio é caráter mais moderado e portanto sua ornamentação é equilibrada e menos exibicionista do que outros papéis similares em óperas do mesmo autor, em tempos passados.

As árias de Fulvia têm demanda de agilidade, mas relativas a cadências de passagem, acabamentos de frase, notas embelezadas, sequências de grupetos, mas nenhuma grande seção melismática como em Ezio ou Valentiniano. O mesmo ocorre com Onoria, embora ela possua esse caráter de bravura, na sua ária do segundo ato.

Todos os papéis, exceto Massimo, foram escritos usando a clave de dó na primeira linha, embora Valentiniano e Fulvia sejam classificáveis atualmente como sopranos, Ezio como um meio-soprano ou soprano grave, e Varo possa ser desempenhado por soprano mais leve. Massimo teve sua música escrita na clave de dó na quarta linha, conforme a convenção da época em que o tenor sendo o registro mais grave da distribuição vocal, assume o caráter do vilão.

O coro, de caráter epigramático, possui uma repetição do texto, numa formulação homorrítmica e de estrutura $a, a^{\prime}$.

A Marcha, bem como a Sinfonia, teve escolhas tradicionais de estrutura. Esta, em três partes, possui um primeiro movimento segundo um modelo de forma-sonata. O movimento central é um cantabile para cordas, estando o terceiro movimento concebido à maneira dos Vivace e Presto do tempo, com estrutura de $3 / 8$ ou $6 / 8$. 
Quadro 2 - Aspectos elementares gerais das árias

Título

Tonalidade Tempo Andamento

Forma

\begin{tabular}{llllll}
\hline Ato 1 & \multicolumn{1}{l}{ Sol M } & $4 / 4 ; 3 / 4$ & $\begin{array}{l}\text { All non Presto/ } \\
\text { Andantino }\end{array}$ & aba \\
\hline Valentiniano: & Se tugi al volo & Sol & & And \\
Ezio & Pensa a serbarmi o cara & SibM & $4 / 4$ & $\begin{array}{l}\text { Affetuoso/Un } \\
\text { poco And. }\end{array}$ & aba \\
\hline Fulvia & Caro padre & Lá M & $4 / 4$ & And. Mod. & rondo \\
\hline Massimo & Nocchier che se figura & Sol M & $3 / 4$ & All Mod & rondo \\
\hline Onoria & Quanto mai fellice siete & Fá M & $6 / 8 ; 2 / 4$ & s.i.t./And & aba \\
\hline Valentiniano & So chi t'accese & Ré M & $4 / 4$ & $\begin{array}{l}\text { All Maestoso/ } \\
\text { Un poco And }\end{array}$ & aba \\
\hline Ezio e Fulvia & M'uccida, m'uccida & SibM & $4 / 4 ; 2 / 4$ & $\begin{array}{l}\text { And. Spiritoso/ } \\
\text { All }{ }^{\circ} \text { assai }\end{array}$ & cavatina \\
\hline
\end{tabular}

Ato 2

\begin{tabular}{|c|c|c|c|c|c|}
\hline Massimo & Va dal furor portata & Dó M & $4 / 4$ & All $^{\circ}$ Vivace & aba \\
\hline Ezio & Recagli quell'acciaro & Ré M & $4 / 4 ; 3 / 8$ & $\begin{array}{l}\text { All }{ }^{\circ} \text { Mod e } \\
\text { Sostenuto/And } \\
\text { Affet. }\end{array}$ & $\mathrm{aba}$ \\
\hline Fulvia & Tenneró per l'idol mio & SibM & $4 / 4 ; 3 / 8$ & $\begin{array}{l}\text { And. Affet./ } \\
\text { And. }\end{array}$ & $\mathrm{aba}$ \\
\hline Varo & Nasce al bosco in rozza & Lá M & $3 / 4 ; 2 / 4 /$ & $\begin{array}{l}\text { And. Vivace/ } \\
\text { And }^{\circ}\end{array}$ & aba \\
\hline Onoria & Fin che per te mi palpita & Mib M & $3 / 8$ & And. Moderato & $a(b) a$ \\
\hline Quarteto & Non trionfar & Sol M & $4 / 4 ; 3 / 4$ & All $^{\circ} /$ And $^{\circ}$ Mod & aba \\
\hline
\end{tabular}

Ato 3

\begin{tabular}{llllll}
\hline Ezio & Tutto il mio sangue & SolM & $4 / 4$ & Allegro & aba \\
\hline Valentiniano & Per tutto il timore & Sib M & $4 / 4 ; 3 / 4$ & n.d. /Andantino & aba \\
\hline Fulvia & Ah, non son io che parlo & Fá M & $6 / 8$ & Allegro & $\begin{array}{l}\text { dal } \\
\text { segno }\end{array}$ \\
\hline Coro Final & $\begin{array}{l}\text { Pela vita nel dubbio } \\
\text { camino }\end{array}$ & Sol M & $3 / 4$ & Allegro & a,a \\
\hline
\end{tabular}

Ao final, os esforços com Ezio apontam a tendência madura, com influências germânicas, de Jommelli, ainda que se associem aspectos típicos do Galante, em especial da opera seria de feitura italiana, fazendo coexistir na partitura elementos então tradicionais e novidades de estrutura e linguagem, resultando num trabalho com características de certo ecletismo. 


\section{Bibliografia}

BRAGA, Teophilo (1871), História do Theatro Portuguez: a baixa comédia e a ópera, seculo XVIII. Lisboa, Imprensa Portugueza..

BRITO, Manuel Carlos de (1982), Opera in Portugal in the Eighteenth Century. Cambridge, Cambridge Press.

ERSKINE, David (ed.) (1954), Augustus Herveys' Journal: beig the intimate account of the life of a capitan in the Royal Navy ashore and afloat, 1746-1759. Londres, William Kimber.

MARTINELLI, Gaetano (1772), Ezio, drama per musica da rapresentarsi nel real teatro dell'ajuda in occasione di festegiarsi il felicissimo giorno natalizio di sua reale maestá l'augustissima signora D. Marianna Vittoria, regina fidelíssima. Lisboa, Stamperia Real.

McCLYMONDS, Marita (1980), Niccoló Jommelli, the last years, 1769-1774. Michigan: UMI.

MONTEIRO, Nuno Gonçalo (2006), Dom José. Rio de Mouros, Circulo de Leitores, 2006.

ROBINSON, Michael (1972), Naples and Neapolitan Opera. Oxford, Clarendon Press.

SANTOS, Mariana Amélia Machado (org.) (1958-1968), Catálogo de Música Manuscrita 9 vols. Lisboa, Ministério da Educação Nacional/Biblioteca da Ajuda.

TWISS, R. (1775), Travels to Portugal and Spain in 1772 and 1773. London, Robinson.

WRAXHALL, Nathaniel (1815), Historical memoirs of my own time, Part the first, from 1772 to 1780. London, Cadell \& Davies, 1815.

\section{Fontes Manuscritas}

Ezio de Niccola Jommelli: manuscrito em três volumes pertencentes à Biblioteca da Ajuda, sob a cota 44-X-11/13 (154pp; 114pp; 62pp). 